\title{
Towards a General Preference System Davld Wall
}

The following is an amencled text of a contribution by $\mathrm{Hr}$. D. Wall to a recent IDS conference on the outcome of UIICTAD 2 which took place at the White Ilouse, Isle of Thorns on May 25 th 1968 .

\section{BACKGROUND}

The resolution of UIICTAD I (Final Act Annex A: III:5) and UNCTAD II (UNCTAD Document No. TD/II/RES/21) on the subject of preferences are substantially the same. The resolution passed in lNew Delhi does not, however, reflect the substantial progress which has been made on the subject since 1964. The four years between the conferences have seen feverish activity in various intergovernmental centres attempting to clarify complex issues involved and to reconcile the conflicting positions of the various countries and groups. At first little progress was made. The turning point came in a speech made by President Johnson to a meeting of Heads of American States at'Punta del. Este early in 1967. In this speech President Johnson said "... we think this idea (preferences) is worth pursuing. We will be discussing it further with members of Congress, with business and lavour leaders, and we will seek the cooperation of other governments in the world trading community to see whether a broad consensus can be reached."

\section{PROGRESS}

It proved fossible for each of the two main negotiating groups - the developed Group B countries and the Group of 77 - to achieve a 'broad consensus' among themselves. The positions of the two groups prior to the New Delhi conference are to be found in UNCTAD DOC. TD/56, which gives the position of the develored (OECD)countries, and UISCTAD DOC. TD/38, the Algiers Charter which gives the position of the Group of 77. It did not prove possible in New Delni, however, for the two negotiating groups to reach a consensus on the details of the proposed General System. of Preferences (GPS). The only visible difference of the outcome of the two conferences on this issue is that whereas at the 1964 conferences the developed countries either voted against or abstained from voting on the preferences resolution, at the 1968 conference the reolution was approved unanimously. In 1964 the problem was to achieve agreement on whether a GPS was desirable or not, in 1968 the problem was what form, in detail, the GPS should take.

\section{CURRENT STATUS OF THE PROPOSAL}

The resolution adofted in New Delhi established a Special Comnittee om preferences, as a subsidiary organ of the UNCTAD Board. The resolution requested that this Committee should meet in November 1968 and should have the objective of settling the details of the arrangements for the G.P.S. in the course of 1969. The resolution concluded by noting "the hope expressed by many countries that the arrangements should enter into affect in early 1970".

\section{MAIN ISSUES}

On the basis of the Algiers Charter and the OECD group report (and contemporary press releases and reports) it is possible to assess which issues are likely to have been the main causes of conflict at New Delhi. The key issues were frobably: i) how to ensure that the least advanced of the less developed countries (LDCs) would benefit from the scheme; $i i)$ what the basis for the exclusion of specific products from the 
outset should be; iii) what 'safety measures' clauses should be incorporated into the sclieme which the developed countries could invoke whon they considered that the 'disruption' of their markets was threatened; iv) what should be the duration of the scheme; v) what to do about existing preference systems, including reverse preferences; and vi) how to ensure equal sharing of the burden of the GPS by the developed countries. These issues are very nuch inter-related, although it seems as if they were treated as separate issues in Hew Delhi. Judging from the evidence available it appears that the key issue was the rroblem presented by the least advanced of the LDCs, particularly in relation to the question of the commodity coverage of the GPS.

In order to provide a focus for the discussion on preferences, the following section will briefly examine these issues and will attempt to define the main points of conflict arising under each of them. It does not pretend to be an exhaustive coverage, and nothing is implied by the order in which they are presented.

\section{The Less Advanced Developing Countries}

The problem is that the preferences system is only intended to cover semi-manufactured and manufactured products; with processed agricultural products being specifically excluded in the OECD report. Thus the benefits would for the most part accrue to those, relatively few, less developed countries which already have well established manufacturing sectors. Those less developed countries, particular those in Africa, who are dependent on exports of agricultural products and only have a primitive industrial sector could not expect to benefit much from a preference system which excluded processed agricultural products. Group of 77 appear to have been The unanimous in their insistence that the
GPS should cover Brusselis Homenclature Groups 1 to 24 . On the other hand there seems to have been disagreement among the developed countries with the extremes represented by the U.S.A. who were in favour of all processed or manufactured goods being included and by France who appear to have insisted on the total exclusion of all processed agricultural products. Between the postions of the U.S.A. and France were several countries who favoured treating processed agricultural products on a case-by-case approach. The impasse on this issue does not seem to have been breached by the end of the conference.

Another point on this issue, referred to in the Algiers Charter, which does not seem to have been taken up in the discussion at New Delhi is that the tine limits of the GPS could be made flexible. This suggestion in effect means that the system would be 'rolling' in that the least advanced LDCs would continue to receive preferences after the more advanced LDCs had ceased to benefit. A rider to this suggestion was that the developed countries should take specific commitrnents of technical add financial assistance to the least advanced $L D C s$ to enable them to take advantage of the GPS. The problem with this suggestion is that it is in direct conflict with the developed ccuntries position that they cannot guarantee any period for the extension of preferences - i.e. they retain the right to negotiate. MFN tariff reductions among themselves.

That the problem or what to do about the least advanced of the LDCs is a very real problem does not seem to have been questioned. The difficulty is what to do about them. The author's view is that the GPS should be seen as part of the global aid programme and that the country by country distribution of capital and technical assistance should take into account the expected and revealed (8) benefits of the GPS received by the different LDCs. 


\section{Exception lists.}

The OECD report makes it clear that before the developed countries could be expected to approve of and implement the GPS they would have to be allowed to publish lists of producta for which they were not prepared to extend preferential treatment to. The rules for the inclusion of a product in the exception lists appear to be i), where an increase in imports of a product would cause injury to domestic industry; ii) where the domestic industry was classified as a sensitive industry and $i i i)$ that the burden of supporting the GPS should be equitably distributed among the developed countries, so that if several of them put a product on their exception lists others would be free to do so too, to prevent their markets from being swarped with imports of the product concerned. Unfortunately no attempt appears to have been made to give any rigorous definition to the concepts 'injury', 'sensitive', and 'burden'. It is obvious that these concepts could be 80 interpreted as to render the GPS totally useless, as all products of export interest to the LDCs could quite conceivably be excluded. This issue seems to have been one in which a protectionist attitude on behalf of the developed countries seems to have prevailed; it is only such an attitude which can give any meaning to such concepts as 'injury', 'sensitivity', and 'burden'. This is obviously. one of the major issues to be resolved in the committee set up to continue the discussion on preferences. The economist has little to contribute to the discussion of this issue as the outcome will depend predominantly on the different strength of the various domestic industrial pressure groups in the leveloped countries.

\section{Safety Measures}

If we assume that meaningful definitions are agreed for the concepts of 'injury', 'sensitivity' and 'burden' then it is clear that in a dynamic world economy industries in developed countries which are not currently regarded as sensitive or subject to injury could come to be so regarded. In this situation it is recognised that there should be some safety measures which the developed countries could invoke to safeguard the interests of their industries. In the words of the OECD report "This would be necessary in order to mitigate the possible effects of increased competition in their markets, or to provide a means of safeguarding the export interests of third countries, whether beneficiary countries or not". (TD/56, ft 27.) In this connection what has to be weigined are, the relative merits of the two most discussed forms that this safeguard mechanism might take, viz.: a system of tariff quotas under which if the clause was invoked the importing country would specify the quantity of imports of a product it was prefared to allow in at the preferential rate of duty, with all imports above this figure being subject to the full MFIN rate and other applicable barriers; a system which if invoked would allow the importing country to limit the quantity of imports of the product concerned to some specific figure, such as a proportion of total domestic consumption, or. domestic production, or the previous years imports. The strongest supporter of the first system has been the U.S.A., and of the latter, France.*

\section{Duration of System}

The OECD document makes it very clear that the GPS is intended by them to be "temporary and subject to periodic review". It is to be regarded as a waiver of the GATT rules and not an obligation. The period suggested in the document is ten years "subject to a major review before this period elapsed in order to determine in the light of circumstances then prevailing whether special treatment should be continued modified, or abolished." ( $t+37$. 
This strong position was taken by the developed countries in order to maintain their freedom to negotiate MFN tariff reductions in GATT. The document takes the line that the LDCs would have to accept that the preferential margin afforded by the GPS could be reduced in this way.

In contrast to tine $O E C D$ position is that of the LDCs. In the Algiers Charter they requested that the GPS be an arrangement which would "last for 20 years and (which) should be reviewed towards the end of this initial period. In any event the Freferential treatment should not there -fore be abruptly terminated." (Page 10, $f+h$.) Despite the ouvious conflict of opening positions of the two sides on this issue it does not seem to have taken up nuch time at New Delhi. The issue seems to reduce to the question of whether the GPS is to be a temporary method of assisting the LDCs to establish competitive manufacturing industry or is envisaged as a new and permanent method of providing aid for the Third World. The developed countries tend towards the former view and the LDCs towards the latter; although no explicit discussion. seems to have taken place on this point. There is also the related question of what is the minimum period in which an LDC can be expected to establish a competitive modern manufacturing indus try.

The question of duration obviously has different implications for LDCs with manufacturing sectors at different s.tages of development. Assuming that the GPS had a fairly wide commodity coverage it is clear that Hong Kong would reap substantial benefit from the outset; for this reason it is probable that both sides would wish to exclude Hong Kong from participation in the scheme. The problem here is to define the crita erion of elegibility for participation in the scheme. If competitiveness is to be the criterion, as would be implied by the exclusion of Hong Kong, then several countries which could hardly be regarded as developed - e.g. India, Pakistan, Taiwan, and llexico - would be in danger of fairly early exclusion from the GPS. The issue here is whe ther the moving spirit underlying the GPS idea is derived from the aid argunent or from the 'infant economy' argurent. 'Need for preferences' is an anbiguous concept.

Existing Preforence Systens

It seems to have been generally agreed (except by the French) that existing preference systems operated by some developed countries in favour of some less developed countries (the most infportant of which are the Commonwealth Preference system and the Yaounde Convention system) should be abolished upon the inauguration of the UNCTAD GPS. This, it was argued, could involve considerable hardship for some of the less developed countries benefiting from the exis.ting systems (the author is not convinced of this) and it seemed generally agreed between the two groups. (Group $B$ and the Group pf 77) at UNCTAD that these countries should be compensated for any losses they might experienqe (the author is not convinced of the' logic of this agreement either). The form of words which reflects the agreement reached on this issu is perhaps represented by the following sentence taken from the Algiers Charter (page 9tt g): "The new system of preferences should ensure at leas $t$ equivalent advantages to developing courtries enjoying preferences in certain developed countries to enable them to suspend their existing preferences on manufactures and semi-manufactures." The difficulty which remains is that it is totally impossible to quantify the concept of "at least equivalent advantages". It is worth noting on this point that the Commonwealth countrles. expressed their willingness to forego their Commonwealth preferences in order to participate in the GPS, as long as the "at leastequivalent advantages were fourthcoming. The French and Francophile 
African countries, however, seem to hav $\$$ insisted that the GPS should be so designed as not to conflict with the benefits of discriminatory preferences received by the Associated States of the E.E.C.

\section{Reverse Preferences}

The U.S.A. has more or less made it a condition of its acceptance of the GPS that existing arrangement under which some developed countries receive prefert ential tariff entry to the markets of some developing countries should be abolished. Of the developed countries currently benefiting from such arrangements it appears that only France took the opportunity presented by New Delhi to make it a major issue. From the evidence it seems that France took the line that the 'costs.' to the developed countries concerned of abolishing reverse preferences should be regarded as part of the burden they were bearing in supporting the GPS. This would seem to have been a tactical move on the part of the French, in an attempt to forestall some of the criticism of the exception list they will eventually produce.

\section{Burden Sharing}

This was not an issue at the New Delhi conference in the same way as those examined above were. Much was made of the notion by the developed countries in their deliberations in the OECD Special Group, as is indicated by the report of the group submitted to UNCTAD. To the author 'burden sharing', or even the notion of the GPS representing a 'burden' at all, is totally meaningless. Can the replacement of uncompetitive, previously protected, domestic production by cheaper imports ever be suitably termed a 'burden' to the importing country? Attention might be usefully directed to the question of whether the concept has been introduced as an evasive tactic by the developed countries to justify the restrictiveness of their negotiating position on various aspects of the GPS, or whether the notion really does refer. to a phenomenon which threatens the successful and meaningful implementation of the GPS.

Further Topics for Discussion

The author would like to suggest two further topics for consideration, without developing them here in any detail. The first is concerned with the likely impact of the successful implementation of the GPS. The second is concerned with how the developed countries might best provide for the accommodation of the GPS in their overall economic planning.

\section{Imnlications of GPS}

Little thought has been given to what the likely effect of a GPS on the international economic situation would be. It seems as though the proposers and opposers of the scheme have beis content to discuss the scheme entirely in relation to either the export prospects of the LDCs taken as a group or in relation to 1 ts impact on the protected industries of the developed countries. Two questions present themselves as candidates for early and urgent research. 1) Would the GPs encourage the rationalization of the location of the world's industry, a the supporters of the System have claimed, or would it result in the emergence of a situation parallel to that prevaliing in the primary commodity market - i.e. surplus production of a variety of manufactured goods? How would the distribution of market opportunities amonget the various LDCs be determined? 2) Would the typa. of industrilization that the GPS encouraged be consistent with the efficlent and equitable development of the LDCs benefiting from the system?

\section{Accommodation of GPS by Developed} Countries

\section{A major problem of the GPS still}

to be faced, is that of seling $1 t$ to the legislatures, industrialists, and 
public of the developed countries. It is important that when this time comes the whole notion, of burden sharing must have been entirely removed from the debate. The public relations work for the GPS should be based on the line that it is in the developed countries own interests. It should be shown that the GPS is complementary to the Kennedy Round for example, and to any further moves toward trade liberalization on a Elobal scale which may be being considered at that time. It could even be argued that such a scheme was essential if full advantage was to be taken by the developed countries of the oprortunities for expanded trade among themselves. 